\title{
THE EFFECT OF INTERMITENT FASTING DIET ON KIDNEY FUNCTION
}

\section{Esa Indah Ayudia ${ }^{1}$ Huntari Harahap ${ }^{2}$ Irfannuddin Irfannuddin ${ }^{3}$}

${ }_{1,2}$ Medical Study Program, Faculty of Medicine and Health Sciences, Jambi University, Jalan Let Jen Suprapto, Jambi City, ${ }_{3}$ Study Program of Medicine, Faculty of Medicine, Sriwijaya University, Jalan Doktor Muhammad Ali, Pahlawan, Sekip Jaya, Palembang City, South Sumatra

Email: Esaindahayudia@gmail.com

\begin{abstract}
Obesity is a condition in which the ratio of body weight and height exceeds the specified standards. Obesity is an increase in total body fat, that is, if you are found to be overweight $>20 \%$ in men and $25 \%$ in women because of fat. The intermittent fasting diet is a calorie restriction method that is widely used for health or weight loss reasons. Overall kidney function is based on nephron function and impaired function is caused by decreased nephron action. Several laboratory tests have been developed to evaluate kidney function and identify the disorder early on. This can help clinicians to take early prevention and management in order to prevent the progression of kidney disorders to kidney failure. Renal function tests are carried out by examining the levels of urea and cretinin.
\end{abstract}

Key words: obesity, intermittent fasting diet, examination of kidney function 


\section{Introduction}

Obesity is a condition in which the ratio of body weight and height exceeds the specified standards. Obesity is an increase in total body fat, that is, if you are found to be overweight $>20 \%$ in men and $25 \%$ in women because of fat . ${ }^{1}$ Obesity occurs when over a period of time, more kilocalories are entered through food than are used to support the body's energy needs, with the excess energy stored as triglycerides in fat tissue. ${ }^{2}$

Nowadays, intermittent fasting diets are gaining popularity . For many people, this diet is considered less restrictive than traditional calorie restriction methods. ${ }^{3}$ This intermittent fasting diet provides many health benefits. The health benefits of an intermittent fasting diet have been demonstrated in randomized controlled trials and observational studies. ${ }^{4}$ The intermittent fasting diet is a calorie restriction method widely used for health or weight loss reasons.

The kidneys play an important role in bodily functions, not only by filtering the blood and removing waste products, but also by balancing electrolyte levels in the body, controlling blood pressure, and stimulating the production of red blood cells. The kidneys have the ability to monitor the amount of body fluids, the concentration of electrolytes such as sodium and potassium, and the acid-base balance of the body. ${ }^{1}$

Overall kidney function is based on nephron function and impaired function is caused by decreased nephron action. Several laboratory tests have been developed to evaluate kidney function and identify the impairment early. This can help clinicians to take early prevention and management in order to prevent the progression of kidney disorders to kidney failure. Renal function tests are carried out by examining urea and cretinin levels. Ureum is the end product of protein and amino acid catabolism that is produced by the liver and distributed through intracellular and extracellular fluids into the blood to be filtered by the glomerulus and partially reabsorbed in a state where urine is disturbed.5 Creatinine is a protein which is the end product of muscle metabolism which is released from muscles at an almost constant rate and is excreted in the urine at the same rate, creatinine is excreted by the kidneys through a combination of filtration and secretion, its concentration is relatively constant in plasma from day to day, the level is higher. a larger than normal value indicates impaired renal function . ${ }^{6}$

\section{Discussion}

\subsection{Kidney Anatomy}

The kidneys play an important role in the excretion of waste products and toxins such as urea, creatinine and uric acid, regulation of extracellular fluid volume, serum osmolality and electrolyte concentration, as well as the production of hormones such as erythropoietin and 1,25 dihydroxyvitamin D and renin. The functional unit of the kidney is a nephron consisting of the glomerulus, proximal and distal tubules, and collecting ducts. Assessment of renal function is important in the management of patients with renal disease or pathologies affecting renal function. Kidney function tests have uses in identifying the presence of kidney disease, monitoring the kidney's 
response to treatment, and determining the progression of kidney disease. According to the National Institutes of Health, the overall prevalence of chronic kidney disease (CKD) is around 14\%. Worldwide, the most common causes of CKD are hypertension and diabetes. ${ }^{7}$

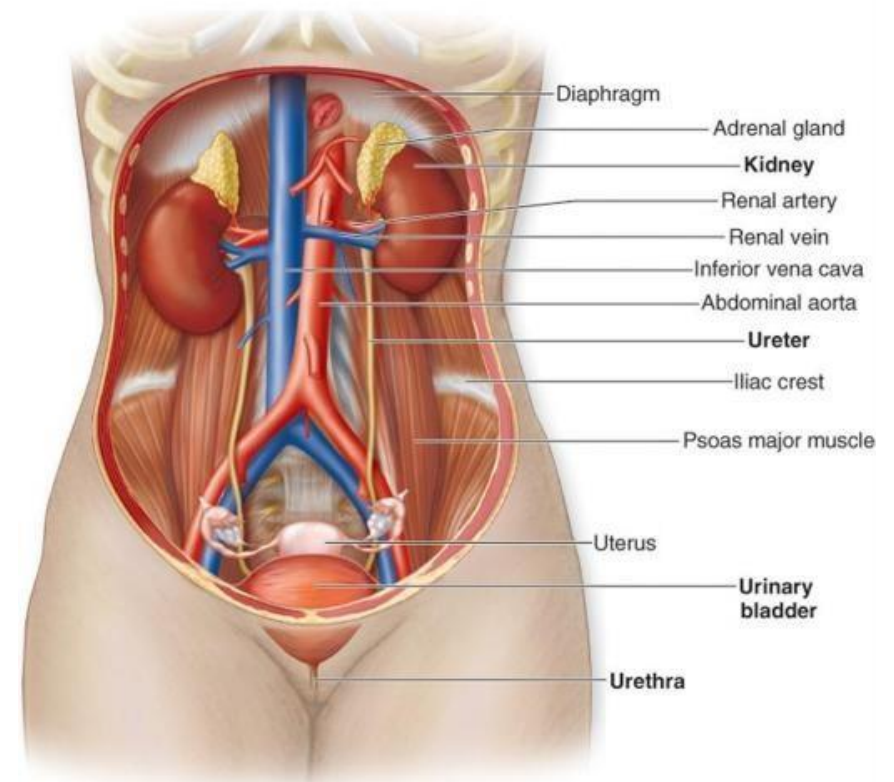

Figure 1. Location of Kidney Anatomy

\section{2 Kidney Physiology}

The kidneys function not only by filtering the blood and removing waste products, but also by balancing electrolyte levels in the body, controlling blood pressure, and stimulating the production of red blood cells. The kidneys have the ability to monitor the amount of body fluids, the concentration of electrolytes such as sodium and potassium, and the acid- base balance of the body . ${ }^{1}$

The kidneys are organs that function to regulate the balance of body fluids by removing waste products from metabolism and holding substances that the body needs. The excretory system itself consists of two kidneys and urinary tract. The kidneys will take harmful substances in the blood and excrete them with urine. The urine will then be collected and drained into the ureter. From the ureter, urine will first be collected into the bladder. If the person feels the urge to take medication and the situation is possible, the urine collected in the bladder will be excreted through the urethra . ${ }^{8}$

\subsection{Renal Function Examination}

\subsection{Ureum Level Examination}

Urea, which is commonly called blood urea nitrogen (BUN) when measured in the blood, is a product of protein metabolism. BUN is considered a non-protein nitrogen (NPN) waste product. Amino acids that come from breaking down proteins are deaminated to produce ammonia. Ammonia is then converted to urea via liver enzymes. Therefore, urea concentration depends on protein intake, the capacity of the body to catalyze protein, and adequate urea excretion by the renal system.

The main waste of protein metabolism is urea or urea. Ureum is a non- protein nitrogen compound in the blood. Ureum is the end product of protein and 
amino acid catabolism which is produced by the liver and distributed through intracellular and extracellular fluids into the blood to be filtered by the glomerulus and partly reabsorbed in a state where urine is disturbed. ${ }^{5}$

The amount of urea in the blood is determined by the protein diet and the ability of the kidneys to excrete urea. If the kidneys are damaged, urea will accumulate in the blood. Increased plasma urea indicates failure of the kidneys to perform its filtration function. A condition of kidney failure characterized by very high plasma urea levels is known as uremia. This situation can be dangerous and requires hemodialysis or kidney transplant . ${ }^{5}$

\section{3.2 Creatinine Levels Check}

Creatinine is a protein which is the end product of muscle metabolism which is released from muscles at an almost constant rate and is excreted in the urine at the same rate, creatinine is excreted by the kidneys through a combination of filtration and secretion, the concentration is relatively constant in plasma from day to day, the level is greater. of normal value indicates impaired kidney function .5

Creatinine levels differ from person to person, generally in muscular people who have higher creatinine levels than those who are not muscular. This also allows the difference in the normal value of creatinine in women and men. The normal value of creatinine in women is $0.5-0.9 \mathrm{mg} / \mathrm{dl}$, while in men it is $0.6-1.1 \mathrm{mg} / \mathrm{dl}$. As an indication, a twofold increase in serum creatinine levels indicates a $50 \%$ decrease in renal function, likewise a threefold increase in creatinine levels indicates a $75 \%$ decrease in renal function. 5

\subsection{Intermittent Fasting Diet in kidney disease}

Diet $\mathrm{p}$ uasa wiper is a method that is widely used calorie restriction for reasons of health or weight loss. The intermittent fasting diet is a diet strategy in which periods of normal food and drink consumption are interspersed with periods of energy restriction or fasting. The classification of $d$ iet intermittent fasting is to limit the feeding time and extend up to 46 hours of fasting the night of 12 to 18 or 20 hours. 9

The classification of the intermittent diet is divided into 3 methods, namely: 1. Alternate-day fasting or fasting into days, which is fasting 24 hours later. During this fast, those who do can only consume $25 \%$ of their total energy needs. After completing the 24 hour fast, those who do may consume any food and drink. 9

2. Modified fasting or fasting 5: 2, namely fasting for 24 hours according to the specified schedule or 2 days of fasting 5 days not fasting. During their fasting period, those who do it can only consume $20-25 \%$ of their total energy needs. During 5 days they did not fasting may eat or drink anything. ${ }^{9}$

3. Time restricted feeding or time restriction, ie fasting for 8 hours to 16 hours per day. This type of fasting is often practiced by Muslims, especially during the month of Ramadan. ${ }^{9}$ 
When fasting glucose is still needed by nerve cells and erythrocytes to produce adenosine triphosphate (ATP) through the process of gluconeogenesis. Gluconeogenesis requires amino acids from breaking down proteins or glycerol from breaking down fats. Amino acids are obtained from the breakdown of protein due to decreased insulin hormone and increased cortisol hormone. Triglyceride lipolysis of adipose tissue releases glycerol and fatty acids. Glycerol will be used for gluconeogenesis and fatty acids will diffuse into muscle fibers and body cells to produce acetyl CoA, which then enters the krebs cycle. Through the kebs cycle and electron transport, the oxidation process can produce ATP. 8,10

During fasting only a small amount of glucose passes through glucolysis to become pyruvic acid, which can then be converted to oxaloacetic acid. Acetyl CoA enters the krebs cycle after combining with oxaloacetic acid, so when the supply of oxaloacetic acid is low due to fasting, only a small amount of acetyl CoA enters the krebs cycle. While the advantages are used for the ketogenesis process. ${ }^{11}$

The production of ketone bodies along with the increased catabolism of fatty acids produces acetyl CoA. Ketone bodies are fat soluble, so they can diffuse through the plasma membrane and cross the blood brain barrier so that they can be used as an alternative fuel for ATP production, especially by neurons, heart muscle, and skeletal muscle. The longer a person fasts with a minimum of food intake, the concentration of ketones in the blood will increase and become a provider of fuel for ATP production. The presence of ketones will reduce the need for gluconeogenesis and slow down muscle protein calabolism . ${ }^{10}$

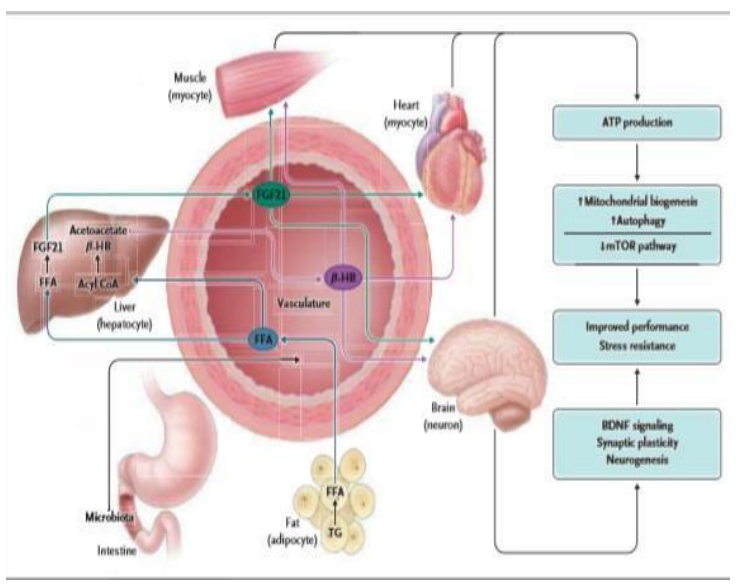

Figure 2. Intermittent Fasting Metabolism 


\section{Conclusion}

The intermittent fasting diet is a calorie restriction method widely used for health or weight loss reasons. Overall kidney function is based on nephron function and impaired function is caused by decreased nephron action.

\section{REFERENCES}

1. Barrett KE, Barman SM, Brooks HL, Yuan JX. Ganong's review of medical physiology. McGraw-Hill Education; 2019.

2. Fuglestad PT, Jeffery RW, Sherwood NE. Lifestyle patterns associated with diet, physical activity, body mass index and amount of recent weight loss in a sample of successful weight losers. International Journal of Behavioral Nutrition and Physical Activity. 2012 Dec 1;9(1):79.

3. Antoni R, Johnston KL, Collins AL, Robertson MD. Effects of intermittent fasting on glucose and lipid metabolism. Proceedings of the Nutrition Society. 2017 Aug;76(3):361-8.

4. Horne BD, Muhlestein JB, Anderson JL. Health effects of intermittent fasting: hormesis or harm? A systematic review. The American journal of clinical nutrition. 2015 Aug 1;102(2):464-70.

5. Sadikin RS. Pemeriksaan Fungsi Ginjal.

6. Myers G. Markers of renal function and cardiovascular disease risk. Cardiovascular. 2012: 43-50.

7. Agur AM, Dalley AF. Grant's atlas of anatomy. Lippincott Williams \& Wilkins; 2009.

8. Guyton AC, John E. Hall textbook of medical physiology. Jackson, Mississippi: Saunders Elsevier. 2011.

9. Malinowski B, Zalewska K, Węsierska A, Sokołowska MM, Socha M, Liczner G, et al. Intermittent fasting in cardiovascular disorders-an overview. Nutrients. 2019;11(3):1- 18.

10. Fauziyati Ana. Adaptasi Fisiologis Selama Puasa. Jurnal Penelitian dan Pengabdian. Univesitas Islam Indonesia. 2008

11. Murray RK, Granner DK, dan Rodwell VW. Biokimia Harper. Edisi ke-27. Jakarta: Penerbit Buku Kedokteran EGC: 2009. Hal. 529-535, 250. 